Available online at GSC Online Press Directory

GSC Biological and Pharmaceutical Sciences

e-ISSN: 2581-3250, CODEN (USA): GBPSC2

(RESEARCH ARTICLE)

\title{
Antibiotic resistance in Escherichia coli from urine of patients with suspected urinary tract infections accessing Dalhatu Araf Specialist Hospital, Lafia, Nigeria
}

\author{
Nkene Istifanus Haruna ${ }^{1}$, Ngwai Yakubu Boyi 1,*, Bassey Bassey Enya ${ }^{2}$, Pennap Grace ${ }^{1}$, Makut Danladi \\ Makwin ${ }^{1}$, Abimiku Rejoice Helma ${ }^{1}$, Ibrahim Taibat ${ }^{3}$ and Tsaku Paul Alumbugu ${ }^{1}$ \\ ${ }^{1}$ Department of Microbiology, Nasarawa State University, P.M.B 1022, Keffi, Nasarawa State, Nigeria. \\ ${ }^{2}$ World Health Organization, Nigeria Country Office, UN House, Plot 617/618, Diplomatic Drive, Central Business District, \\ P.M.B. 2861, Garki, Abuja, Nigeria \\ ${ }^{3}$ Department of Science Laboratory Technology, Nasarawa State University, P.M.B. 1022, Keffi, Nasarawa State, Nigeria.
}

Publication history: Received on 31 July 2019; revised on 16 August 2019; accepted on 20 August 2019

Article DOI: https://doi.org/10.30574/gscbps.2019.8.2.0146

\begin{abstract}
The wide use of antibiotics to treat urinary tract infection (UTIs) caused by bacteria is compromised by the development of resistance mechanisms in bacteria. This study evaluated the antibiotic resistance in Escherichia coli from urine of patients with suspected UTI in Dalhatu Araf Specialist Hospital, Lafia, Nigeria. Four hundred urine samples of suspected UTI patients were collected and E. coli was isolated and identified using standard microbiological methods. Antimicrobial Susceptibility Testing for the isolates was carried out and interpreted as described by the Clinical and Laboratory Standards Institute (CLSI). The occurrence of the bacterium was $14.5 \%$ $(58 / 400)$. The occurrence was higher in female $(15.8 \%)$ than the male $(12.5 \%)$; and highest at $>50$ years $(31.8 \%)$. The isolates were more resistant to ampicillin (79.3\%), streptomycin $(62.0 \%)$ and cefoxitin (58.6 \%) but less resistant to gentamicin (15.8\%), imipenem (18.9\%) and amoxicillin/clavulanic acid (27.6\%). The occurrence of multi-drug resistance (MDR) isolates was 87.9\%. The antibiotics namely gentamicin, imipenem and amoxicillin/clavulanic acid were very effective against the isolates and most of the isolates were MDR. There is thus a need for the hospital to limit its antibiotic use in the light of these observations.
\end{abstract}

Keywords: Escherichia coli; Urine; Antibiotics; Resistance

\section{Introduction}

Escherichia coli are one of the most common clinically relevant and multi-drugs resistant (MDR) bacteria causing both community and hospital acquired Urinary Tract Infection (UTIs) [1]. The UTIs are one of the most common infections diagnosed in hospital setting especially in developing countries [2]. Antibiotics have been successfully used for treatment of UTIs cause by member of family Enterobacteriaceae especially E. coli [2] but emergence of strains of the isolates resistance to commonly prescribed antibiotics have been reported worldwide [2,3,4,5,6] and this however have continued to be a threat to public health due to management of this infection caused by MDR strains [2].

The emergence of antibiotic resistant strains of $E$. coli causing UTIs have been reported in several studies worldwide $[7,8]$. The MDR strains of this isolates causing UTIs have increase the cost of therapy, morbidity and mortality especially in developing countries [9], hence there is a need for continue surveillance of antibiotic resistant strains of bacteria causing UTIs especially in third world countries for proper management to reduce the risk of morbidity, mortality and economic loss to the patients and nation. This study however investigates the antibiotic resistance in $E$. coli from urine of patients with suspected UTIs in Dalhatu Araf Specialist Hospital Lafia, Nigeria.

\footnotetext{
${ }^{*}$ Corresponding author

E-mail address: ngwaiyb@yahoo.com
} 


\section{Material and methods}

\subsection{Study location and sample collection}

The study location was the Dalhatu Araf Specialist Hospital, Lafia, Nasarawa State, Nigeria. A total of four hundred (400) early morning mid-stream urine samples of patients with suspected UTIs attending the health facility were collected using sterile container and transported using ice pack to the Microbiology Laboratory at Nasarawa State University, Keffi for analysis.

\subsection{Isolation of Escherichia coli}

Escherichia coli was isolated from urine samples as follows: a loopful of urine sample will be streaked on MacConkey Agar plate and incubated at $37^{\circ} \mathrm{C}$ for $24 \mathrm{~h}$. Pinkish colonies that grew on MacConkey agar were further streaked on Eosin Methylene Blue Agar and incubated at $37^{\circ} \mathrm{C}$ for $24 \mathrm{~h}$. Greenish metallic sheen colonies that grew on the Eosin Methylene Blue agar plate were selected as presumptive E. coli.

\subsection{Identification of Escherichia coli}

The presumptive E. coli was Gram-stained, and biochemically identified as suspected E. coli using IMViC (Indole, Methyl red, Voges-Proskauer and Citrate) tests as earlier described [10]. The suspected E. coli isolates (Gram negative, rod shape, indole positive, methyl red positive, citrate negative and Voges-Proskauer negative) were using a commercial biochemical testing kit (KB003 H125TM) following the manufacturer's instruction.

\subsection{Antimicrobial susceptibility testing}

The antimicrobial susceptibility testing of the bacterial isolates was carried out as earlier described by Clinical and Laboratory Standards Institute [11]. Briefly, three (3) pure colonies of the isolates were inoculated in to $5 \mathrm{ml}$ sterile $0.85 \%(\mathrm{w} / \mathrm{v}) \mathrm{NaCl}$ (normal saline) and the turbidity of the bacteria suspension will be adjusted to the turbidity equivalent to 0.5 McFarland's standard. The McFarland's standard was prepared as follows: $0.5 \mathrm{ml}$ of $1.172 \%(\mathrm{w} / \mathrm{v}$ ) $\mathrm{BaCl}_{2} .2 \mathrm{H}_{2} \mathrm{O}$ was added into $99.5 \mathrm{ml}$ of $1 \%(\mathrm{w} / \mathrm{v}) \mathrm{H}_{2} \mathrm{SO}_{4}$.

A sterile swab stick was soaked in standardized bacteria suspension and streaked on Mueller-Hinton agar plates and the antibiotic discs were aseptically placed at the centre of the plates and allowed to stand for $1 \mathrm{~h}$ for pre-diffusion. The plates were incubated at $37^{\circ} \mathrm{C}$ for $24 \mathrm{~h}$. The diameter zone of inhibition in millimetre was measured and the result was interpreted in accordance with the susceptibility break point earlier described by Clinical and Laboratory Standards Institute [11].

\subsection{Determination of multiple antibiotics resistance (MAR) index}

The MAR index of the isolates was determined using the formula: MAR Index = No. antibiotics isolate is resistant to/No. of antibiotics tested as described previously [12].

\subsection{Classification of antibiotics resistance}

Antibiotic resistance in the isolates were classified into: multidrug resistance (MDR: non-susceptible to $\geq 1$ agent in $\geq$ 3 antimicrobial categories); extensive drug resistance (XDR: non-susceptible to $\geq 1$ agent in all but $\leq 2$ antimicrobial categories); pan drug resistance (PDR: non-susceptible to all antimicrobial listed) [13]. 


\section{Results}

Table 1 Cultural, Morphological and Biochemical characteristics Escherichia coli from Urine of Patients with Suspected Urinary Tract Infection in Dalhatu Araf Specialist Hospital, Lafia, Nigeria

\begin{tabular}{|c|c|c|}
\hline \multicolumn{2}{|c|}{ Cultural Characteristics } & $\begin{array}{l}\text { Pinkish colony on MCA and greenish } \\
\text { metallic sheen colony EMB agar }\end{array}$ \\
\hline \multirow{2}{*}{$\begin{array}{l}\text { Morphological } \\
\text { Characteristics }\end{array}$} & Gram stain & - \\
\hline & Morphology & rod \\
\hline \multirow{12}{*}{$\begin{array}{l}\text { Biochemical } \\
\text { Characteristics }\end{array}$} & ONPG & + \\
\hline & Ornithine & + \\
\hline & UR & - \\
\hline & LYS & + \\
\hline & NT & + \\
\hline & $\mathrm{H}_{2} \mathrm{~S}$ & - \\
\hline & CT & - \\
\hline & TDA & - \\
\hline & $\mathrm{VP}$ & - \\
\hline & MR & + \\
\hline & IND & + \\
\hline & MAL & - \\
\hline \multicolumn{2}{|l|}{ Inference } & E. coli \\
\hline
\end{tabular}

MCA = MacConkey agar; EMB = Eosin methylene blue; UR = Urease; LYS = Lysine; $\mathrm{H}_{2} \mathrm{~S}=$ Hydrogen Sulphide; CT = Citrate; TDA = Phenylalanine deaminase; $\mathrm{VP}=$ Voges-Proskauer; $\mathrm{IND}=$ Indole; $\mathrm{MAL}=$ Malonate $;$ - = Negative $;+$ = Positive

Table 2 Occurrence of Escherichia coli from Urine of Patients with Suspected Urinary Tract Infection in Dalhatu Araf Specialist Hospital, Lafia, Nigeria in Relation to Gender

\begin{tabular}{lll}
\hline Gender & No. of Samples & No. (\%) E. coli \\
\hline Male & 160 & $20(12.5)$ \\
Female & 240 & $38(15.8)$ \\
Total & 400 & $58(14.5)$ \\
\hline
\end{tabular}

Table 3 Occurrence of Escherichia coli from Urine of Patients with Suspected Urinary Tract Infection in Dalhatu Araf Specialist Hospital, Lafia, Nigeria in Relation to Gender in Relation to age

\begin{tabular}{lll}
\hline Age & No. of Samples & No. (\%) E. coli \\
\hline$\leq 10$ & 48 & $10(20.8)$ \\
$11-20$ & 81 & $18(22.2)$ \\
$21-30$ & 72 & $6(8.3)$ \\
$31-40$ & 127 & $13(10.2)$ \\
$41-50$ & 50 & $4(8.0)$ \\
$>50$ & 22 & $7(31.8)$ \\
Total & 400 & $58(14.5)$ \\
\hline
\end{tabular}


Table 4 Antibiotic Resistance of Escherichia coli from Urine of Patients with Suspected Urinary Tract Infection in Dalhatu Araf Specialist Hospital, Lafia, Nigeria

\begin{tabular}{lll}
\hline Antibiotics & Disc Content $(\boldsymbol{\mu g})$ & No. (\%) Resistance (n=58) \\
\hline Amoxicillin/clavulanic acid (AMC) & 30 & $16(27.6)$ \\
Ampicillin (AMP) & 30 & $46(79.3)$ \\
Ceftazidime (CAZ) & 30 & $30(51.7)$ \\
Cefotaxime (CTX) & 30 & $33(56.9)$ \\
Cefoxitin (FOX) & 30 & $34(58.6)$ \\
Ciprofloxacin (CIP) & 5 & $29(50.0)$ \\
Gentamicin (CN) & 10 & $9(15.8)$ \\
Imipenem (IPM) & 30 & $11(18.9)$ \\
Streptomycin (S) & 30 & $36(62.1)$ \\
Sulphamethoxazole/trimethoprim (SXT) & 25 & $34(58.6)$ \\
\hline
\end{tabular}

Table 5 Antibiotic Resistant Phenotypes of Escherichia coli from Urine of Patients with Suspected Urinary Tract Infection in Dalhatu Araf Specialist Hospital, Lafia, Nigeria

\begin{tabular}{ll}
\hline Antibiotic Resistance Phenotypes & DASHL (n=58) \\
\hline AMP & $1(1.7)$ \\
FOX-IMP & $1(1.7)$ \\
SXT-AMP & $1(1.7)$ \\
FOX-AMP & $2(3.4)$ \\
S-AMP & $1(1.7)$ \\
SXT-FOX-AMP & $1(1.7)$ \\
S-FOX-AMP & $1(1.7)$ \\
S-SXT-AMP & $1(1.7)$ \\
CIP-SXT-AMP & $1(1.7)$ \\
S-SXT-FOX-AMP & $3(5.2)$ \\
CTX-CAZ-FOX-CIP & $1(1.7)$ \\
S-FOX-IPM-AMP & $1(1.7)$ \\
CTX-CAZ-CIP-AMP & $1(1.7)$ \\
SXT-FOX-CN-CIP-AMP & $1(1.7)$ \\
CTX-CAZ-FOX-CIP-AMP & $1(1.7)$ \\
AMC-S-CTX-CAZ-SXT & $1(1.7)$ \\
CTX-CAZ-CIP-SXT-AMP & $1(1.7)$ \\
S-CTX-CAZ-FOX-AMP & $1(1.7)$ \\
AMC-CTX-CAZ-SXT-AMP & $1(1.7)$ \\
AMC-S-CTX-CN-AMP & $1(1.7)$ \\
S-SXT-FOX-UPM-CIP-AMP & $1(1.7)$ \\
AMC-S-SXT-CTX-FOX-AMP & $1(1.7)$ \\
S-SXT-CTX-FOX-CIP-AMP & $1(1.7)$ \\
S-SXT-CTX-CAZ-CIP-AMP & $8(13.8)$ \\
CTX-CAZ-FOX-CIP-SXT & $1(1.7)$ \\
AMC-S-CTX-FOX-IPM-AMP & $1(1.7)$ \\
S-SXT-CTX-CAZ-FOX-CIP & $1(1.7)$ \\
S-SXT-CAZ-FOX-CIP-AMP & $1(1.7)$ \\
S-CTX-CAZ-FOX-CIP-AMP & $1(1.7)$ \\
AMC-S-SXT-CTX-CAZ-CN-AMP & $1(1.7)$ \\
AMC-S-SXTR-CTX-CAZ-CIP-AMP & $1(1.7)$ \\
S-CTX-CAZ-FOX-CN-IMP-AMP & $1(1.7)$ \\
S-SXT-CTX-CAZ-FOX-CIP-AMP & $2(3.4)$ \\
AMC- S-SXT-CTX-CAZ-FOX-CN-CIP-AMP & $5(8.6)$ \\
AMC-SXT-CTX-CAZ-FOX-IPM-CIP-AMP & $1(1.7)$ \\
AMC-S-CTX-CAZ-FOX- IPM-CIP-AMP & $1(1.7)$ \\
AMC-S-SXT-CTX-CAZ-FOX-CN-CIP-AMP & $2(3.4)$ \\
S-SXT-CTX-CAZ-FOX-CN-IPM-CIP-AMP & $4(6.9)$ \\
AMC- S-SXT-CTX-CAZ-FOX-CN-IPM-CIP-AMP & $1(1.7)$ \\
\hline
\end{tabular}

$\mathrm{AMC}=$ Amoxillin/Clavulanic acid; $\mathrm{S}=$ Streptomycin; $\mathrm{SXT}=$ Suphamethoxazole/Trimethoprim; $\mathrm{AMP}=$ Ampicillin; $\mathrm{CTX}=$ Cefotaxime; $\mathrm{CAZ=Ceftazidime;}$ FOX=Cefoxitin; $\mathrm{CN}=$ Gentamicin; IPM=Imipenem; CIP=Ciprofloxacin 
Table 6 Multiple Antibiotic Resistance (MAR) Index of Escherichia coli isolated from Urine of Patients with Suspected Urinary Tract Infection in Dalhatu Araf Specialist Hospital, Lafia, Nigeria

\begin{tabular}{ccccc}
\hline $\begin{array}{l}\text { No. of Antibiotics Resistance } \\
\text { (a) }\end{array}$ & $\begin{array}{l}\text { No. of Antibiotic tested } \\
\text { (b) }\end{array}$ & $\begin{array}{l}\text { MAR } \\
\text { (a/b) }\end{array}$ & Index & $\begin{array}{l}\text { Frequency } \\
\text { (n=58) }\end{array}$ \\
\hline 10 & & 10 & 1.0 & $1(2.0)$ \\
9 & & 10 & 0.9 & $4(8.0)$ \\
8 & 10 & 0.8 & $5(10.0)$ \\
7 & 10 & 0.7 & $5(10.0)$ \\
6 & 10 & 0.6 & $12(24.0)$ \\
5 & 10 & 0.5 & $7(14.0)$ \\
4 & 10 & 0.4 & $6(12.0)$ \\
3 & 10 & 0.3 & $4(8.0)$ \\
2 & 10 & 0.2 & $5(10.0)$ \\
1 & 10 & 0.1 & $1(2.0)$ \\
\hline
\end{tabular}

Table 7 Classes of Antibiotic Resistance in Escherichia coli isolated from Urine of Patients with Suspected Urinary Tract Infection in Dalhatu Araf Specialist Hospital, Lafia, Nigeria

\begin{tabular}{ll}
\hline Categories of Antibiotic Resistance & Frequency (\%) (n=58) \\
\hline NMDR & $1(1.7)$ \\
MDR & $51(87.9)$ \\
XDR & $5(8.6)$ \\
PDR & $1(1.7)$ \\
\hline Multi-drug resistance; MDR=Multi-drug resistance; XDR=Extensive drug reistance; PDR=Pandrug resistance
\end{tabular}

\section{Discussion}

The isolation of $E$. coli from urine of suspected UTIs patients in the study centre was expected and this agree with the study earlier reported by Rami'rez-Castillo et al. [14] and El-Boumri et al. [15], that E. coli is one of the is the most common agent of UTIs. The percentage occurrence of the isolates in the study centre was similar with the studies earlier reported by El-Boumri et al. [15] in India, Eko et al. [16] in Keffi, Nigeria, Eghieye et al. [2] and Rami'rezCastillo et al. [14] in Mexico. The occurrence of the isolates was higher than $12.1 \%$ reported by Eghieye et al. [2] but less than $54.0 \%$ reported by El-Boumri et al. [15].

The occurrence of the isolates in relation to the age of suspected UTIs patients was high in $>50$ years and these findings is not in agreement with the study earlier reported by Eghieye et al. [2] and Rami'rez-Castillo et al. [14] who reported high occurrence of the isolates in 41-50 years (50.0\%) and 2-10 years (29.0\%). The high percentage of the isolates in $>50$ years may be due to the fact that individual at that age grouped may have low immune status and may be more prone to UTIs.

The high percentage occurrence of the isolates of the isolates in female than male was expected and these findings agree with the study earlier described by Eghieye et al. [2], Rami'rez-Castillo et al. [14] and Giwa et al. [17]. The high occurrence of the isolates in female than the male counterpart may be due to differences in the anatomy of the reproductive organ where female have short reproductive organ than the male counterpart and this may therefore enables the female to be more prone to UTIs (2), although the percentage occurrence of the isolates in relation to gender was statistically insignificant and this implies that gender may not necessarily be a factor for occurrence of the isolates.

Our findings in this study shows that isolates were more resistance to ampicillin, ceftazidime, cefotaxime, cefoxitin, streptomycin and sulphamethoxazole/trimethoprim and this is not different from the study earlier described by Eko 
et al. [16] and Eghieye et al. [2]. The percentage resistance of the isolates to the antibiotics mentioned was less than $93.0 \%, 60.5 \%, 53.7 \%, 72.1 \%, 56.0 \%$ and $86.0 \%$ resistance to ampicillin, ceftazidime, cefotaxime, cefoxitin, streptomycin and sulphamethoxazole/trimethoprim as earlier reported by Eko et al. (2018). The resistance of the isolates to antibiotic mentioned may be due to inappropriate use of the antibiotics during therapy of the infection caused by the isolates.

The occurrence of multi-drug resistance isolates in urine of patients with suspected UTIs suggest that the isolates may likely be responsible for UTIs that is difficult to treated since MDR isolates are responsible for life threatening UTIs that is difficult to be treated [18]. The percentage occurrence of the MDR isolates higher than $56.1 \%$ and $64.9 \%$ reported by Parajuli et al. [18] and Hashemizadeh et al. [19] but less than $93.5 \%$ and $84.6 \%$ reported by Eko et al. [16] and Eghieye et al. [2].

\section{Conclusion}

The occurrence of E. coli in the urine of suspected UTIs patients was low. The isolates were least resistant to the antibiotics and the antibiotics namely amoxicillin/clavulanic acid, imipenem and gentamicin, and may be useful for empirical treatment of UTIs. In addition, most of the isolates were MDR.

\section{Compliance with ethical standards}

\section{Acknowledgments}

The authors wish to acknowledge all contributions by the staff of Microbiology laboratory. Dalhatu Araf Specialist Hospital, Lafia

\section{Disclosure of conflict of interest}

Authors have declared that no competing interests exist.

\section{References}

[1] Nkene IH, Ngawi YB, Omede MU, Samuel J, Envuladu EY and Abimiku RH. (2015). Extended spectrum betalactamase producing Escherichia coli from urine of symptomatic and asymptomatic subjects in Keffi, Nigeria. International Journal of Research Studies in Biosciences, 3(12), 1-5.

[2] Eghieye MO, Jodi SM, Bassey BE, Nkene IH, Abimiku RH and Ngwai YB. (2018). Antimicrobial resistance profile of Escherichia coli isolated from urine of patients in selected General Hospitals in Abuja Municipal, Nigeria. Asian Journal of Advanced Research and Report. 2(2), 1-10.

[3] Mishra MP, Sarangi R and Padhy RN. (2016). Prevalence of multi-drug resistant uropathogenic bacterial in pediatric patients of Tertiary Care Hospital in Estern India. Journal of Infection and Public Health, 9(3), 308314.

[4] Niranjan V and Malim A. (2014). Antimicrobial resistance pattern in Escherichia coli causing Urinary Tract Infections among inpatients. Indian Journal of Medical Research, 139(4), 945-948.

[5] Ferjani S, Saidani M, Amine FS and Boubaker IBB. (2015). Prevalence and characterization of plasmid-mediated quinolone resistance genes in extended-spectrum $\beta$-lactamase-producing Enterobacteriaceae in a Tunisian hospital. Microbial Drug Resistance, 21(2), 158-166.

[6] Tajbakhsh E, Parvin A, Elham A, Nazila A and Faham K. (2016). Biofilm formation, antimicrobial susceptibility, serogroups and virulence genes of uropathogenic E. coli isolated from clinical samples in Iran. Antimicrobial Resistance and Infection Control, 5 (11), 2-8.

[7] Olson RP, Harrel LJ and Kaye KS. (2009). Antimicrobial resistance in urinary Escherichia coli from college women with Urinary Tract Infections. Antimicrobial Agent and Chemotherapy, 53(3), 1285-1286.

[8] Morill HJ, Morton JB, Caffery AR, Jiang L, Dosa D, Mormel LA and Laplente KI. (2017). Antimicrobial Resistance of Escherichia coli urinary isolates in Veterans affairs Health Care System. Antimicrobial Agent and Chemotherapy, 61(5), 02236-16. 
[9] Schito GC, Naber KG, Botto H, Palou J, Mazzei T and Gualco L. (2009). The ARESC study: an international survey on the antimicrobial resistanceof pathogens involved in uncomplicated urinary tract infections. International Journal of Antimicrobial Agents, 34, 407-13.

[10] Cheesebrough M. (2006). Medical Laboratory Manual for Tropical Countries. Cambridge: Cambridge University Press, 49-97.

[11] Clinical and Laboratory Standards Institute. (2017). Performance Standards for Antimicrobial Susceptibility Testing; 27nd Informational Supplement M100-S22. Wayne, Pa, USA.

[12] Ngwai YB, Gyar SD, Pennap GRI, Makut MD, Ishaleku D, Corosi SM, Nkene IH and Uzoamaka N. (2014). Antibiogram of non-sorbitol fermenting Escherichia coli isolated from environmental sources in Keffi, Nigeria. NSUK Journal of Science and Technology, 4 (1\&2), 152-163.

[13] Magiorakos AP, Srinivasan A, Carey R, Carmeli Y, Falagas M, Giske C and Olsson-Liljequist B. (2012). Multidrugresistant, extensively drug-resistant and pandrug-resistant bacteria: an international expert proposal for interim standard definitions for acquired resistance. Clinical microbiology and infection, 18(3), 268-281.

[14] Rami'rez-Castillo FY, Moreno-Flores AC, Ave'lar-Gonza'lez F, Ma'rquez-Diaz F, Harel J and Guernero-Barrera AL (2018). An evaluation of Multi-drug resistance Escherichia coli isolates in Urinary Tract Infections from Aguascalients, Mexico; cross-sectional study. Annal Clinical Microbiology and Antimicrobial, 17, 1-13.

[15] El-bouamri MC, Arsalane L, Zerouali K, Katfy K, El kamouni Y and Zouhair S. (2015). Molecular characterization of extended spectrum _lactamase-producing Escherichia coli in a university hospital in Morocco, North Africa. African Journal of Urology, 21, 161-166.

[16] Eko KO, Jodi SM, Nkene IH, Abimiku RH, Ibrahim T and Ngwai YB. (2018). Antimicrobial Resistance Profile of Escherichia coli from urine of patients in Nagari Allah Magani Hospital, Keffi, Nigeria. Asian Journal of Research in Medical and Pharmaceutical Sciences, 5(4), 1-9.

[17] Giwa FJ, Ige OT, Haruna DM, Yaqub Y, Lamido TZ and Usman SY. (2018). Extended-spectrum $\beta$-lactamase production and antimicrobial susceptibility pattern of uropathogens in a tertiary hospital in North-Western, Nigeria. Annals of Tropical Pathology, 9(1), 11-16.

[18] Parajuli NP, Maharjan P and Parajul H. (2017). High rate of multi-drug resistance among uropathogenic Escherichia coli in children and analysis of Extended-spectrum $\beta$-lactamase producers from Nepal. Antimicrobial Resistance, Infection and Control, 6 (1), 9.

[19] Hashemizadeh Z, Kalantar-Neyestanaki D and Mansouri S. (2018). Clonal relationship, antimicrobial susceptibility and molecular characterization of Escherichia coli isolates from urinary tract infection and feacal samples in South East Iran. Revista da Sociedade Brasileira de Medicina Tropical 51 (1), 11-19.

\section{How to cite this article}

Nkene IH, Ngwai YB, Bassey BE, Pennap G, Makut DM, Abimiku RH, Ibrahim T and Tsaku PA. (2019). Antibiotic resistance in Escherichia coli from urine of patients with suspected urinary tract infections accessing Dalhatu Araf Specialist Hospital, Lafia, Nigeria. GSC Biological and Pharmaceutical Sciences, 8(2), 106-112. 